\title{
Cuestionario de actitudes frente a situaciones de agravio. Resultados preliminares de su adaptación al ámbito escolar
}

\author{
Veronica Caminos ${ }^{1}$ y Laura B. Oros ${ }^{2}$ \\ ${ }^{1}$ Licenciada en Psicología. Universidad Adventista del Plata ${ }^{10}{ }^{2}$ Doctora en Psicología. \\ Universidad de la Cuenca del Plata-CONICET; Universidad Adventista del Plata- ${ }^{12}$ Instituto \\ Superior Adventista de Misiones.
}

Recibido: 08 de noviembre de 2016

Aceptado: 08 de enero de 2017

\section{Resumen}

Se adaptó al ámbito docente el Cuestionario Argentino de Actitudes frente a Situaciones de Agravio (Moreno y Pereyra, 2000). Para su validación preliminar se trabajó con 143 docentes argentinos. Los ítems resultaron discriminativos y se agruparon, a partir de un Análisis Factorial Exploratorio, en tres dimensiones que están en línea con la teoría: Pasividad $(\alpha=.90)$, Agresividad $(\alpha=.95)$ y Prosocialidad $(\alpha=.92)$. La validez constructiva también se puso a prueba mediante el estudio de la hipótesis que afirma que los docentes con alto Burnout tienen mayor tendencia a responder con actitudes negativas en situaciones de agravio en el contexto áulico. Estos resultados también estuvieron en línea con la teoría $(p<.001)$. A partir de estos análisis se concluye que la versión preliminar del instrumento es apta para ser sometida a estudios psicométricos más exigentes y de mayor alcance.

Palabras claves: Actitudes - Agravio - Docencia - Escolar

\begin{abstract}
The Argentine Questionnaire on Attitudes vis-a-vis Situations of Aggression (Moreno y Pereyra, 2000) was adapted to the educational environment. For its preliminary validation, 143 Argentine teachers participated. The items turned out to be discriminative and they were grouped, based on a Factorial Exploratory Analysis, into three dimensions that are related to the theory: Passivity $(\alpha=$ $.90)$, Aggressiveness $(\alpha=.95)$ and Prosocial behavior $(\alpha=.92)$. The constructive validity was also tested by analyzing the hypothesis that confirms teachers with a high level of burnout syndrome have a greater tendency to behave negatively when faced with situations of aggression in the
\end{abstract}

${ }^{2}$ Correspondencia al autor

E-mail: fachuin2@uap.edu.ar 
classroom context. These results were also related to the theory $(p<.001)$. Based on these analyses, it is concluded that the preliminary version of the instrument is apt for submission to psychometric studies of a more rigorous nature and wider

Keywords: Attitudes - Situations of Aggression - Education - School

\section{Introducción}

Es preocupante cómo, cada vez con mayor frecuencia, conceptos como agresión, violencia, sometimiento y acoso, cobran notoriedad en ámbitos en los cuales hasta hace algún tiempo era impensable su manifestación. La escuela constituye uno de estos ámbitos en donde las agresiones que en ella se producen desencadenan en mayor o menor medida problemas serios que involucran tanto al docente como al alumnado.

Son diversas las manifestaciones de la violencia en el ámbito escolar y pueden presentarse de manera física, en la forma de maltrato de instalaciones y material mobiliario, peleas entre alumnos y ataques hacia docentes; de manera verbal en la forma de insultos y burlas; y de manera psicológica, expresada como amenazas entre alumnos $y / 0$ hacia el docente y como el entorpecimiento o impedimento adrede del transcurso y desarrollo de las clases (Marín, 2002).

Dentro de esta temática ha recibido históricamente mayor interés el deterioro de las relaciones alumno-alumno, sin embargo es acuciante la necesidad de explorar la relación alumnodocente, debido a que se ve cada vez más entorpecida por los elevados índices de hostigamiento psicológico que reciben los educadores.

Según Gómez (2014), este fenómeno que ya ha sido estudiado y tratado desde hace varios años, a nivel internacional ha generado algunas investigaciones para tomar iniciativas respecto a diversas instituciones educativas de Estados Unidos, España, Tailandia, Japón, Perú y Brasil, entre otras. Los resultados de las investigaciones en dichos países muestran que el fenómeno de la violencia escolar, específicamente del alumnado hacia el docente, ha aumentado alarmantemente, tanto en la manifestación de conductas que desafían la autoridad, como la afección de la integridad física de los docentes a través de los ataques físicos hacia su persona y sus bienes.

Según Abad (2002):

Cada vez más, los trabajadores de la educación deben enfrentar obstáculos y limitaciones que impiden que su labor sea placentera o simplemente que se pueda llevar a cabo. En ciertos contextos, sufren 
coerciones y verdaderas mortificaciones cotidianas (Ulloa 1995, citado en Abad, 2002). Pocos docentes logran elaborar las permanentes frustraciones y transformar el malestar en creatividad; muchos desarrollan mecanismos defensivos y actitudes polares de ataque (agresión y autoagresión) o de fuga (abandono de la tarea o sometimiento acrítico); mientras otros pueden mostrar comportamientos relacionados con la desafectivización del rol, cierta indiferencia que se traduce en rutinización y apatía. El docente es frecuentemente violentado y puede violentar (pág. 41).

Es sabido que cuando una persona se encuentra bajo presión, producto de infinidad de variables, suele responder con menor tolerancia y mayor irritabilidad frente a las exigencias o agravios de los demás. En el caso de la relación docente - alumno, reacciones inadecuadas del docente frente a provocaciones del alumno, pueden aumentar el nivel de tensión en ambas partes implicadas, haciendo más importante el agravio y más hostil la respuesta. Se instala entonces un círculo vicioso de desórdenes y reacciones, en lugar de una interacción satisfactoria para todos.

La educación se caracteriza por ser un proceso en el cual están involucrados de manera conjunta educador y educando. Por ello, cuando por los motivos que fueren, la relación entre ambas partes se encuentra afectada, los resultados son perjudiciales tanto para el maestro como para el alumno y la institución en su conjunto. Una institución educativa que avala actitudes que desestiman al docente y que tolera la violencia hacia su persona, entorpece significativamente los necesarios procesos de colaboración, transformación y cambio que resultan positivos para la sociedad (Díaz y Rodríguez, 2010).

\section{Actitudes hacia el agravio}

Según Silar (2004), el agravio genera sorpresa, decepción, pena, vergüenza y temor. Una vez que se genera el malestar como producto de la ofensa, aparece en primera instancia el distanciamiento entre las partes, acompañado de reacciones diversas que van desde la culpa, la tristeza y la ansiedad hasta el resentimiento, la hostilidad, el rencor y la venganza (Moreno y Pereyra, 2000; Rodríguez y Moreno, 2013).

Por lo tanto, ante un agravio, la víctima puede vivir diferentes experiencias de malestar vinculadas al dolor y el enojo configurándose, de acuerdo al modelo teórico de Moreno y Pereyra (2000), tres posibles tipos de respuestas (pasivas, agresivas y prosociales) que involucran a su vez siete actitudes diferentes, que serán transcriptas a continuación (Moreno y Pereyra, 2000, pp 1524). 


\section{Respuestas pasivas}

Las conductas pasivas o inhibidas son compatibles con actitudes conformistas o de aceptación del agravio, que se desarrollan con el fin de conservar la estabilidad interior y el control de las propias pulsiones agresivas, como recurso para superar, sobrellevar o intentar anular la situación agraviante. En esta dimensión se distinguen dos modalidades de respuesta:

1. Sometimiento: las actitudes sumisas hacia el entorno se caracterizan por la aceptación pasiva y la tendencia a evitar el conflicto. La escasa confianza en sí mismas, lleva a estas personas a intentar alcanzar una sensación de seguridad mediante la simple aceptación de las normas impuestas por personalidades más fuertes o autoritarias. El sometido no inicia acción alguna, aguarda a que otros dirijan o reaccionen frente a un problema o situación. Rara vez manifiestan la agresión abierta y pocas veces la encubierta. Existe entonces, una conducta de subordinación del juicio, la decisión o los afectos propios a la actitud del ofensor; por lo general, mediante justificaciones humillantes.

2. Negación: En el contexto de las relaciones interpersonales, se da como una respuesta consistente en excluir del campo de la conciencia el objeto perturbador. La negación cierra la mente a todo aquello que se presenta como amenazante. Los procesos de negación se activan cuando no hay una alternativa constructiva frente al daño o la amenaza. Tiene por finalidad aliviar el grado de trastorno producido por la situación, sin alterar el funcionamiento del individuo ni producir daño adicional. A diferencia del sometimiento, que apunta a un control interno del impulso agresivo, la negación intenta controlar los estímulos externos que amenazan activar la agresividad y destruir el equilibrio personal.

\section{Respuestas agresivas}

En esta dimensión se distinguen tres modalidades de respuesta:

1. Hostilidad: El concepto de hostilidad suele ser utilizado de forma intercambiable con el de cólera. Esta actitud se asocia a una amplia variedad de fenómenos emocionales como la irritabilidad, el enfado, la rabia, el enojo, la ira, el disgusto y el cinismo, entre otros. Se pueden distinguir en la hostilidad tres componentes: el cognitivo, el afectivo y el conductual. El primero consiste en las creencias negativas acerca de otras personas. Los sujetos hostiles suelen atribuir a otros el no ser confiables o poseer conductas inmorales, lo cual facilita juzgarlos como amenazantes 
y enemigos. El segundo componente, el afectivo, es el contenido nuclear de la hostilidad, que comprende las emociones negativas, en sus diversos grados. Las investigaciones han mostrado que cuando estas manifestaciones perduran en el tiempo, se convierten en factores patogénicos de muchas enfermedades, en particular de las cardiovasculares. El tercer componente es el conductual y comprende las diversas modalidades, físicas y verbales, de agresión. Este aspecto ha sido uno de los más estudiados debido a las consecuencias sociales que provoca (violencia, delincuencia, conductas antisociales) como a los efectos en el mismo sujeto (conductas suicidas o autopunitivas).

2. El resentimiento: el núcleo primordial del resentido consiste en sentirse dolido y no querer o no poder olvidar. La persona se desvive imaginando de qué forma puede dañar al otro, sin embargo, las injurias y los contraataques planeados, el desahogo "rumiado", suelen quedar en el plano mental sin realizarse (en esto se diferencia con el vengativo). Este deseo agresivo que no llega a concretarse aprisiona al individuo en el recuerdo de lo sucedido, dejándolo fijado en el pasado.

3. La venganza: Según Ugarte (2000): Se trata de una conducta premeditada de búsqueda intencional del desquite por medio de un castigo similar o superior al padecido. El sentimiento de rencor impulsa a la revancha y se busca un ajuste de cuentas, no dejando las cosas tal y como han quedado. El razonamiento se formula así: me has hecho mucho daño con tu manera de actuar y lo pagarás antes o después, sea como sea (párr.11).

Siguiendo con Moreno y Pereyra (2000): es importante destacar que la venganza posee un componente cognitivo nuclear que consiste en planificar fría y deliberadamente una respuesta dañina al ofensor. A diferencia de la reacción hostil, que es primaria e inmediata, supone un control de la agresividad y una búsqueda de la satisfacción en el momento adecuado, con el propósito de causar el mayor perjuicio posible.

\section{Respuestas prosociales}

Continuando con lo que postula Moreno y Pereyra, (2000, p. 22-25), "los comportamientos prosociales implican la realización de acciones que tienden a beneficiar a otras personas, grupos $\mathrm{u}$ organizaciones sociales sin que exista la previsión de una recompensa exterior".

En esta dimensión se distinguen dos modalidades de respuesta: 
1. Búsqueda de explicación: es la actitud que lleva a clarificar la discordia afrontando la cuestión, centrándose en el problema en lugar de en la emoción. El reclamo o búsqueda de explicación implica demandar al ofensor justificaciones y motivos que den cuenta de su proceder, exigiendo recuperar o reparar, total o parcialmente, el daño ocasionado, como condición necesaria para reparar el vínculo. Está muy vinculado al concepto psicológico de asertividad.

2. Perdón-reconciliación: Enright (1989, citado en Moreno y Pereyra, 2000) ha definido el perdón como: "la capacidad que un individuo posee para sobrellevar una injusticia y reestablecer una relación de amor con los otros" (p. 24).

El autor consideró esta expresión del perdón como el estadio más desarrollado de la evolución moral en la personalidad. Se trata de un acto que suscita y promueve sentimientos de afecto, cerrando las puertas a las acciones de venganza y permitiendo la posibilidad de la reconciliación. El perdón promueve la indulgencia y la tolerancia, la benevolencia y la abnegación, la actitud de grandeza de pedir o conceder la disculpa. Todo esto suele ser, la mayor parte de las veces, condición indispensable para hacer posible la reconciliación, lo que convierte el perdón en el camino de acceso privilegiado para reanudar la comunicación y el intercambio satisfactorio. En forma específica, la palabra "reconciliación" se traduce como "la acción de restituir relaciones quebrantadas". Consiste en restablecer la amistad o las buenas relaciones, eliminar el desacuerdo y recuperar el entendimiento y la armonía (Moreno y Pereyra, 2000).

\section{Evaluación de las actitudes frente al agravio}

Con base en el modelo precedente, Moreno y Pereyra (2000) desarrollaron un sistema de medida para evaluar las diferentes actitudes de una persona frente a las situaciones de agravioofensa que pueden vivenciar por parte de otros sujetos. Se trata de un cuestionario que consta de 10 relatos hipotéticos de situaciones de ofensa, pertenecientes a cinco ámbitos diferentes (laboral, amistoso, paterno-filial, de pareja, y de trascendencia espiritual). En cada relato se presentan siete alternativas de respuestas posibles, correspondientes a cada una de las escalas previstas (sometimiento, negación, hostilidad, resentimiento, venganza, búsqueda de explicación y perdónreconciliación). El sujeto debe identificarse con la víctima y responder cada una de las siete alternativas, graduadas en cuatro opciones: nunca, casi nunca, frecuentemente y siempre. Las propiedades psicométricas de la escala han resultado medianamente satisfactorias (sometimiento 
$\alpha=0.56$, negación $\alpha=0.70$, venganza $\alpha=0.77$, resentimiento $\alpha=0.78$, hostilidad $\alpha=0.79$, búsqueda de explicación $\alpha=0.64$ y perdón-reconciliación $\alpha=0.65$ ) (Moreno y Pereyra, 2000).

En la Tabla 1 se puede apreciar como ejemplo un relato del ámbito laboral y sus posibles opciones de respuesta.

Tabla 1.

Ejemplo de relato del ámbito laboral.

El jefe de personal de la empresa me autorizó en dos oportunidades a faltar al trabajo para acompañar a mi hijo al médico. Sin embargo, a fin de mes me envió un telegrama de despido alegando que faltaba en forma injustificada. Por esto yo:

Siempre Frecuentemente Pocas Siempre veces

No le dirigiría más la palabra ni nunca más lo saludaría

Trataría por todos los medios de lograr que lo despidan a él

A pesar de todo, mantendría una relación amistosa para que en el futuro no brinde malas referencias, si las piden en otro trabajo

Trataría de hablar con él para que me diga porqué se comportó así conmigo

Buscaría otro trabajo, mejor es dejarlo pasar

Le diría que es un desleal, mentiroso y traicionero

Conversaría con él acerca de lo sucedido y mantendría abierta la posibilidad de reconciliación.

Con el objetivo de adquirir un mayor acercamiento del modo en que el docente se relaciona con el alumno, particularmente cuando sufre algún tipo de agravio de parte del educando, es que resulta prometedor llevar a cabo la adaptación al ámbito escolar del Cuestionario de Actitudes frente a Situaciones de Agravio. 
Actualmente hay investigaciones que se centran en el estudio general de la violencia o agresividad escolar entre los diferentes actores que la integran, pero hay pocos estudios que se dedican a evaluar específicamente los tipos de respuestas de los docentes frente a las situaciones de agravio hacia su alumnado. Dado que los educadores son agentes formadores de los aspectos no sólo intelectuales sino también morales y emocionales, y que su salud, bienestar y estilo de relacionamiento son cruciales para lograr dichos objetivos, se considera importante conocer cómo se posicionan frente a situaciones interaccionales complejas del ambiente áulico. Los datos obtenidos podrían ser el puntapié inicial para el diseño de estrategias e intervenciones específicas que favorezcan el desarrollo y fortalecimiento de recursos para potenciar un relacionamiento óptimo entre ambas partes involucradas, y por lo tanto un clima escolar agradable para el desempeño laboral y académico, favoreciendo funciones básicas que son necesarias para la enseñanza y el aprendizaje.

Teniendo en cuenta estas consideraciones, la presente investigación se abocó a la adaptación al ámbito escolar del Cuestionario de Actitudes frente a Situaciones de Agravio (Moreno y Pereyra, 2000), y a la exploración preliminar de sus propiedades psicométricas.

\section{Método}

\section{Participantes}

Los docentes fueron seleccionados de manera no aleatoria, en función de la disponibilidad que mostraron los directivos escolares para que el equipo de investigación tomara contacto con su personal. Participaron voluntariamente 143 docentes que ejercían su labor en los tres ciclos de la Educación General Básica, de 14 escuelas públicas y privadas a las que asisten en su mayoría alumnos de clase social media, pertenecientes a las ciudades de Pedro Luro, Mayor Buratovich, Juan A. Pradere, Hilario Ascasubi, y Dolores en la provincia de Buenos Aires; Gallareta en la provincia de Santa Fe; y Crespo y Diamante en la provincia de Entre Ríos.

El 94\% $(n=135)$ correspondió al sexo femenino y el $6 \%$ al sexo masculino $(n=8)$, y las edades oscilaron entre $\operatorname{los} 20$ y $\operatorname{los} 60$ años $(M=38 ; D E=7,86)$. A pesar de la evidente desproporción por género, se decidió mantener este pequeño porcentaje de hombres debido a tres razones: (a) la función docente se caracteriza por un predominio de profesionales mujeres, por lo que esta diferencia es simplemente un reflejo de la realidad; (b) no interesa analizar la posible 
incidencia del sexo sobre la variable dependiente; y (c) los resultados se mantienen casi con exactitud al excluir estadísticamente a los docentes hombres.

Esta muestra $(n=143)$ se utilizó para estudiar el funcionamiento psicométrico del instrumento. Otra muestra, compuesta por aproximadamente 100 docentes con características similares, y un grupo de 10 sujetos en calidad de expertos, fueron seleccionados previamente para realizar el proceso inicial de adaptación cualitativa (ver detalles en el acápite Procedimientos de adaptación).

\section{Instrumento}

Se utilizó la versión original del Cuestionario de Actitudes frente a Situaciones de Agravio (C.A.S.A) de Moreno y Pereyra (2000), para llevar a cabo la adaptación de dicho instrumento al ámbito escolar.

\section{Procedimientos de adaptación}

En primer lugar, con el objetivo de crear nuevos relatos que expresaran situaciones de agravio provenientes del alumnado, se solicitó a aproximadamente 100 docentes, seleccionados intencionalmente para que presentaran similares características a las que tendrían los docentes de la muestra final, que narraran hasta cuatro situaciones en las cuales se hubieran sentido ofendidos, agraviados, humillados o agredidos por un alumno. Se recolectaron 75 encuestas, de las cuales 62 contenían una, dos, tres o cuatro situaciones que el docente experimentaba como ofensa; la cantidad restante de encuestas estaba en blanco, ya que los docentes acotaron que no vivenciaban situaciones de este estilo.

Posteriormente, se procedió a realizar un análisis de contenido de las situaciones para determinar las que se repetían con mayor frecuencia. Tras este análisis preliminar, se seleccionaron 12 situaciones que sirvieron para confeccionar los 12 relatos compuestos por 7 ítems cada uno.

Esta versión inicial fue sometida al criterio de 10 jueces (psicólogos y estudiantes avanzados de la carrera de psicología) con el objetivo de que los mismos evaluaran la adecuación de la propuesta de operacionalización al modelo teórico del cual se desprendía. Hubo una coincidencia absoluta y positiva respecto a esta adecuación por lo que no fue necesario realizar modificaciones a ninguno de los relatos con sus respectivos ítems. El cuestionario adaptado al ámbito escolar, al 
igual que en la versión original de Pereyra y Moreno (2000), contiene por cada relato siete ítems; correspondientes a cada tipo de respuesta frente al agravio. Cabe aclarar que se reemplazó el nombre de la escala Sometimiento de la versión original, por el de Justificación inadecuada, debido a que el sometimiento es propio de la relación entre pares, y en este caso la relación docente-alumno es asimétrica.

El encuestado, en este caso el docente, debe identificarse con la víctima del relato y responder a cada alternativa de las siete presentadas, eligiendo para cada una de ellas sólo una de las cinco opciones de respuestas enunciadas (nunca, casi nunca, a veces, frecuentemente y siempre), para reconocer cómo actuaría ante determinada situación que es presentada en el cuestionario. Cabe aclarar aquí también, que la frecuencia de respuestas fue modificada, agregándosele la dimensión a veces, pues se consideró que en la versión original no había un punto intermedio de respuesta.

\section{Procedimiento para la recolección de datos}

En primer lugar, se solicitó autorización a la dirección correspondiente de cada escuela para acceder a su cuerpo docente, además de explicar en qué consistía el presente trabajo y cuáles eran los objetivos. Si bien se contaba con la aprobación de la dirección, los docentes podían elegir si completar los cuestionarios o no. La gran mayoría aceptó sin problemas, pues el tema les interesaba en sobremanera. En algunos casos, los cuestionarios fueron administrados en momentos donde el docente disponía de una hora libre. En otros casos, en que el docente no podía completarlo en el momento, se le explicaba la manera en que debía hacerlo y se acordaba entregarlo luego de un tiempo establecido. Otra de las maneras utilizadas para recolectar los datos consistió en ir al domicilio donde residía el docente, y una vez que accedía a colaborar en la investigación, se procedía a explicarle la manera en que debía completar cada uno de los cuestionarios para posteriormente volver al lugar y recogerlos.

\section{Procedimiento para el análisis de datos}

Para estudiar el funcionamiento del cuestionario adaptado, se realizó un análisis del poder discriminativo de los ítems, mediante la prueba T para grupos contrastantes; se ejecutó un análisis de consistencia interna (alpha de Cronbach) para cada una de las dimensiones evaluadas; se realizó un Análisis Factorial Exploratorio (AFE) con el mismo método de extracción y rotación que 
utilizaron los autores del cuestionario (ejes principales y rotación varimax); y se efectuó un análisis de validez de constructo, mediante el estudio de la hipótesis que afirma que existe una relación significativa y positiva entre el síndrome de Burnout docente y la tendencia a responder con actitudes negativas en situaciones de agravio generadas en el contexto áulico. Esta hipótesis fue puesta a prueba mediante una correlación $r$ de Pearson, fijando un nivel de significación del 5\%.

Con respecto al AFE, cabe destacar que el mismo ha sido realizado como una aproximación preliminar al estudio de la estructura del cuestionario, ya que el tamaño muestral no cumple con los criterios habitualmente exigidos para este tipo de análisis: mínimo de 5 sujetos por cada ítem de la escala (Gorsuch, 1983), o tamaño mínimo muestral de 200 casos (Comrey y Lee, 1992). Por lo tanto, los resultados de este análisis en particular deberán considerarse orientativos y no concluyentes.

\section{Resultados}

Respecto al poder discriminativo, los resultados de la prueba $t$ de diferencia de medias indicaron que todos los ítem de la versión adaptada tienen una buena capacidad discriminante $(p<$ .001). Con relación a la validez del instrumento, la escala fue estudiada factorialmente para conocer cómo se agrupaban los ítems. Se analizó la matriz de correlación mediante el test de esfericidad de Bartlett, que obtuvo un valor significativo $\left(\square^{2}=7700,289 ; p<.001\right)$; y el test KMO, que alcanzó un valor de .747 . En un principio y de acuerdo al criterio teórico utilizado, se hipotetizó la existencia de siete factores correspondientes a cada una de las siete escalas que componen dicho instrumento, hipótesis que además estuvo apoyada por el gráfico de sedimentación. Sin embargo, tras la extracción se observaron cuatro factores principales, que explicaron el $46.80 \%$ de la variancia, y tres factores residuales. El primer factor agrupó los ítems de las escalas de Justificación inadecuada y Negación, correspondientes a la dimensión de Respuestas pasivas; el segundo factor englobó los ítems de las escalas de Hostilidad, Resentimiento y Venganza, correspondientes a la dimensión de Respuestas agresivas; el tercer factor estuvo compuesto por los ítems de la escala de Búsqueda de explicación, correspondiente a la dimensión de Respuestas prosociales; y el cuarto factor reunió los ítems de la escala de Perdón, correspondiente también a la dimensión de Respuestas prosociales.

En vista de este ordenamiento lógico, se realizó una refactorización extrayendo tres factores generales que explican el $36.94 \%$ de la variancia total. El primero y el segundo factor no mostraron 
modificaciones respecto al análisis anterior; mientras que el tercero y el cuarto factor se fusionaron en uno solo, mostrando así coherencia teórica. Para cada uno de los tres factores, se mantuvieron los ítems que mostraron una saturación por encima de .30. Fueron eliminados los que no cumplieron con dicha condición y los que resultaron factorialmente complejos, por lo que la versión definitiva quedó integrada por 76 ítems de los 84 originalmente propuestos. En la Tabla 2 se presenta la distribución de los ítems, omitiendo los pesos factoriales inferiores a .30.

Tabla 2.

Dimensiones y pesos factoriales de los ítems del Cuestionario de Actitudes frente a Situaciones de Agravio

\begin{tabular}{|c|c|c|c|}
\hline \multicolumn{4}{|l|}{ Matriz de factor rotado ${ }^{a}$} \\
\hline & \multicolumn{3}{|c|}{ Factor } \\
\hline & 1 & 2 & 3 \\
\hline $\begin{array}{l}\text { Lo tomaría como un hecho circunstancial y sin importancia, } \\
\text { después de todo no es el único libro que utilizo }\end{array}$ &, 035 &,- 080 & ,401 \\
\hline No se puede pretender que todos presten atención &, 016 &,- 027 &, 356 \\
\hline $\begin{array}{l}\text { A veces a uno le toca ser el centro de las burlas, no por eso me } \\
\text { voy a hacer problema }\end{array}$ &, 010 &, 074 & ,503 \\
\hline Hay que aceptar si ése es su modo de comunicarse &,- 004 &,- 081 &, 537 \\
\hline $\begin{array}{l}\text { Hay que entenderlo, después de todo, uno está a disposición del } \\
\text { alumno }\end{array}$ &,- 036 &, 138 & ,600 \\
\hline $\begin{array}{l}\text { Tendría paciencia con él, después de todo, fue solamente uno el } \\
\text { que me desobedeció }\end{array}$ &,- 135 &, 160 &, 534 \\
\hline $\begin{array}{l}\text { No les llamaré la atención, después de todo, no es tan grave lo que } \\
\text { hicieron }\end{array}$ &, 016 & ,033 &, 572 \\
\hline $\begin{array}{l}\text { Hay que aceptarlo si él es de esa manera, quizá hice algo que } \\
\text { provocó esa actitud en él }\end{array}$ &,- 067 &, 041 &, 543 \\
\hline
\end{tabular}




\begin{tabular}{|c|c|c|c|}
\hline Sólo estaba jugando, no hay que ser tan estricta &,- 020 &, 002 &, 623 \\
\hline No se puede pretender llevarse bien con todos los alumnos &,- 012 &, 014 &, 551 \\
\hline Haría como que no escuché lo que me dijo & ,086 &,- 054 & ,473 \\
\hline Hay que seguir adelante y no cuestionarse tanto las cosas & ,084 &,- 018 & ,441 \\
\hline Haría como que no escuché o no vi &,- 072 & ,003 &, 541 \\
\hline Hay cosas mas importantes por las cuales preocuparse &,- 001 &,- 026 & ,731 \\
\hline Es preferible no hacerse más problema y olvidar lo sucedido &,- 032 &,- 050 & ,561 \\
\hline No le daría importancia a lo sucedido &,- 102 &,- 035 & ,677 \\
\hline Haría como que no vi nada &, 145 &,- 017 &, 579 \\
\hline Haría como que no pasó absolutamente nada & ,080 &,- 197 & 579 \\
\hline Lo tomaría como un hecho sin importancia &,- 062 &, 015 & ,683 \\
\hline Haría como que no me di cuenta de su actitud hacia mi &,- 031 &,- 070 & ,713 \\
\hline Siempre me acordaría del mal momento que me hizo pasar & ,547 &,- 053 &,- 041 \\
\hline En todo momento me acordaría de lo que me hizo & ,586 &,- 006 & ,022 \\
\hline Siempre tendría presente lo que me hizo & ,692 &,- 052 &,- 044 \\
\hline $\begin{array}{l}\text { Todo el tiempo me acordaría del momento desagradable que me } \\
\text { hicieron pasar }\end{array}$ & ,709 &,- 077 &, 085 \\
\hline Voy a tener en cuenta que se burló de mí, cada vez que lo vea & ,758 &,- 155 & 013 \\
\hline $\begin{array}{l}\text { Aunque se disculpe, ésta es una ofensa que siempre tendré } \\
\text { presente }\end{array}$ &, 589 &,- 154 &,- 002 \\
\hline $\begin{array}{l}\text { Cada vez que lo vea, me acordaría de su actuar desinteresado y } \\
\text { desagradecido }\end{array}$ &, 642 &,- 020 &,- 008 \\
\hline Tendría siempre bien presente lo que me hizo &, 715 &,- 091 &,- 093 \\
\hline Tendré presente en todo momento su actitud &, 726 &,- 176 &,- 064 \\
\hline Jamás olvidaría lo que me hizo & ,454 & ,001 & ,091 \\
\hline
\end{tabular}




\begin{tabular}{|c|c|c|c|}
\hline Cada vez que lo vea, tendría bien presente lo que me hizo &, 710 &,- 112 &, 063 \\
\hline Jamás me olvidaría de la actitud que tuvo hacia mí &, 535 &,- 094 &,- 026 \\
\hline Le expresaría todo mi enojo y bronca & ,589 &,- 057 &,- 024 \\
\hline Le llamaría la atención de manera muy enojada & ,545 & ,079 &,- 127 \\
\hline Le gritaría todo lo que se merezca & ,703 &,- 095 &, 036 \\
\hline Muy enojada les diré lo mal que me pone que se comporten así & ,561 & ,088 &,- 047 \\
\hline Me enojaría terriblemente con él & ,678 & ,050 &,- 105 \\
\hline Le llamaría la atención muy enojada & ,594 & ,086 &,- 036 \\
\hline Con bronca le diré lo que siento por su actitud desconsiderada & 680 &,- 120 &,- 025 \\
\hline Ni bien entre al aula, enojada, le llamaría la atención & ,611 & ,051 &,- 089 \\
\hline $\begin{array}{l}\text { Les diría muy enojada y con bronca lo que significa que me hagan } \\
\text { eso }\end{array}$ & ,684 &,- 073 &,- 013 \\
\hline $\begin{array}{l}\text { Terriblemente enojada por su conducta hacia mí, le diré todo lo } \\
\text { que se merece }\end{array}$ & ,657 &,- 134 & ,032 \\
\hline Le expresaría todo mi enojo & ,725 &,- 065 &, 034 \\
\hline Me enojaría terriblemente con él & ,702 &,- 123 &,- 011 \\
\hline Esperaría el momento para castigarlo como corresponde & ,357 & ,085 &,- 017 \\
\hline Cuando pudiera le mostraría cuan mala puedo ser & ,572 &,- 025 & ,066 \\
\hline Le pondría todas las sanciones que pueda & ,662 &,- 106 &, 032 \\
\hline $\begin{array}{l}\text { En alguna ocasión le haría sentir todo lo que significa ser } \\
\text { humillado de ésa manera }\end{array}$ & ,522 &,- 096 & ,097 \\
\hline $\begin{array}{l}\text { Le llamaría la atención por su incumplimiento, delante de todo el } \\
\text { curso }\end{array}$ & ,357 & ,053 &, 163 \\
\hline Esperaría la ocasión para castigarlo como corresponda & ,517 &,- 026 &,- 053 \\
\hline Buscaría la manera de castigarlo como se merezca & ,610 &,- 012 &,- 018 \\
\hline Cuando menos lo espere, le daré su merecido & ,604 &,- 199 & ,096 \\
\hline
\end{tabular}




\begin{tabular}{|l|l|l|l|}
\hline Esperaría la situación para castigarlo como corresponde &, 421 &,- 082 &, 025 \\
\hline Después de clase, a solas, le pediría explicación de su proceder &,- 194 &, 337 &,- 054 \\
\hline Hablaría con él después, para que me diga por que actuó así &,- 203 &, 399 &,- 111 \\
\hline Le pediría explicación acerca de lo ocurrido &,- 283 &, 547 &,- 136 \\
\hline $\begin{array}{l}\text { Me acercaría a ellos y a solas, les preguntaría por qué se } \\
\text { comportaron de esa manera }\end{array}$ &,- 232 &, 406 &,- 138 \\
\hline $\begin{array}{l}\text { Le preguntaría cuales fueron los motivos que lo hicieron actuar } \\
\text { de esa manera }\end{array}$ &,- 233 &, 488 &,- 069 \\
\hline $\begin{array}{l}\text { A la salida de clase, le preguntaría por qué se comportó conmigo } \\
\text { de esa manera }\end{array}$ &,- 110 &, 404 &,- 084 \\
\hline Oportunamente le preguntaría por qué me desobedeció &,- 075 &, 552 &,- 039 \\
\hline $\begin{array}{l}\text { Trataría de hablar con ellos para que me expliquen por qué se } \\
\text { comportaron así }\end{array}$ &,- 246 &, 547 &,- 108 \\
\hline Cuando se tranquilice, le pediría una explicación por lo que hizo &,- 167 &, 376 &,- 056 \\
\hline $\begin{array}{l}\text { Le preguntaría por los motivos que lo llevaron a comportarse de } \\
\text { determinada manera }\end{array}$ &,- 125 &, 527 &,- 050 \\
\hline $\begin{array}{l}\text { Hablaría después con él a solas, para pedirle explicación acerca } \\
\text { de su actitud }\end{array}$ &,- 196 &, 548 &,- 123 \\
\hline $\begin{array}{l}\text { Después de darle la sanción que corresponda, si percibo que está } \\
\text { arrepentido de la manera en que actuó, lo perdonaría }\end{array}$ &, 070 &, 433 &,, 110 \\
\hline $\begin{array}{l}\text { Si luego de aplicarle la sanción adecuada, me pide disculpas, lo } \\
\text { perdonaría }\end{array}$ &, 086 &, 594 &,, 140 \\
\hline $\begin{array}{l}\text { Luego de sancionarlo debidamente, hablaría con él para saber por } \\
\text { qué actuó así, y si reconsidera su proceder lo perdonaría }\end{array}$ &, 124 &, 597 &, 022 \\
\hline $\begin{array}{l}\text { Una vez aplicada la sanción debida, si me piden disculpas por su } \\
\text { actitud, los perdonaría }\end{array}$ &, 149 &, 576 &, 098 \\
\hline $\begin{array}{l}\text { Lo disciplinaría como corresponda y si percibo que realmente se } \\
\text { siente mal por lo que me hizo y me pide que lo perdone, le daría } \\
\text { una nueva oportunidad }\end{array}$ &, 148 &, 593 &,- 115 \\
\hline
\end{tabular}




\begin{tabular}{|l|l|l|l|}
\hline $\begin{array}{l}\text { Si luego de aplicarle la medida disciplinaria correspondiente, } \\
\text { percibo que recapacita acerca de lo que hizo, aceptaría su } \\
\text { arrepentimiento }\end{array}$ & $, 061,747,145$ \\
\hline $\begin{array}{l}\text { Si luego de sancionarlo, me doy cuenta de su arrepentimiento por } \\
\text { lo que hizo, no tendría problema en darle una nueva oportunidad }\end{array}$ &,- 015 &, 672 &, 046 \\
\hline $\begin{array}{l}\text { Lo disciplinaría y si luego se muestra arrepentido, lo disculparía } \\
\text { Una vez aplicada la sanción, lo perdonaría si me doy cuenta que } \\
\text { está arrepentido }\end{array}$ &, 011 &, 760 &, 049 \\
\hline $\begin{array}{l}\text { Después de tomar las medidas disciplinarias correspondientes, } \\
\text { aceptaría sus disculpas si noto su arrepentimiento }\end{array}$ &, 073 &, 729 &, 091 \\
\hline $\begin{array}{l}\text { Si posterior a la aplicación de la sanción correspondiente, me pide } \\
\text { disculpas, las aceptaría sin problemas }\end{array}$ &,- 103 &, 678 &, 112 \\
\hline $\begin{array}{l}\text { Luego de colocarle la sanción conveniente, si reconsidera su } \\
\text { proceder, lo perdonaría }\end{array}$ &,- 031 &, 814 &, 031 \\
\hline $\begin{array}{l}\text { Método de extracción: factorización de eje principal. } \\
\text { Método de rotación: Varimax con normalización Kaiser. }\end{array}$ & \\
\hline a. La rotación ha convergido en 4 iteraciones. & & \\
\hline
\end{tabular}

En cuanto a la consistencia interna, el índice alpha de Cronbach resultó entre muy bueno y excelente para los tres factores emergentes: Respuestas pasivas $(\alpha=.90)$; compuesto por 20 items; Respuestas agresivas $(\alpha=.95)$ compuesto por 33 items, y Respuestas prosociales $(\alpha=.92)$ compuesto por 23 ítems.

Con respecto al estudio de la validez de constructo, se observó una correlación positiva y significativa entre el síndrome de Burnout docente y las respuestas agresivas ante el agravio $(r=$ $.41 ; p<.001)$, y una correlación negativa y significativa entre el síndrome y las respuestas prosociales $(r=-.39 ; p<.001)$. No se observó correlación alguna con las respuestas pasivas $(r=$ $.09 ; p=2.89)$. 


\section{Discusión y conclusiones}

La interacción humana cualquiera sea su ámbito de acción está caracterizada en muchos casos por conductas agresivas, violentas, ofensivas y/o agraviantes. El ámbito escolar no es ajeno a dichas interacciones. A través de la literatura es posible encontrar investigaciones y variados estudios que dan cuentan de esta realidad, particularmente entre alumnos. Con el paso del tiempo y la profundización del estudio cada vez mayor de la realidad escolar, se le ha dado paulatinamente más importancia también al estudio e investigación de las características de vinculación del docente hacia el alumno. Específicamente, con el objetivo de adquirir un mayor acercamiento acerca del modo en que el docente se relaciona con el alumno, puntualmente cuando sufre algún tipo de agravio de parte del educando, es que se propuso llevar a cabo la adaptación al ámbito escolar del Cuestionario de Actitudes frente a Situaciones de Agravio.

El proceso de adaptación y de validación provisoria, ha dado como resultado una nueva versión del cuestionario, con 76 ítems referidos a 12 relatos (entre 5 y 7 ítems por cada uno) y 5 opciones de respuesta. Los relatos incluidos en esta versión se pueden considerar significativos debido a que no han sido propuestos arbitrariamente sino que han emergido tras un profundo trabajo de análisis de las experiencias reales de más de 60 docentes argentinos en ejercicio de su labor.

Las evidencias de validez recogidas indican que el instrumento mide con precisión el constructo que se ha propuesto evaluar. La estructura factorial resultó clara y ajustada a los presupuestos teóricos, a pesar de que las respuestas de los docentes no se agruparon en función de las siete reacciones particulares ante el agravio, propuestas por Moreno y Pereyra (2000). Es preciso enfatizar, no obstante, que autores como Ferrando y Anguiano-Carrasco (2010) y LloretSegura, Ferreres-Traver, Hernández-Baeza y Tomás-Marco (2014) recomiendan un tamaño muestral de al menos 200 casos para la realización del Análisis Factorial Exploratorio, aún en condiciones de óptima comunalidad y factores claramente definidos; aspecto que no se ha alcanzado en este estudio. Por tal motivo, y a pesar de que la adaptación realizada cumple satisfactoriamente con los criterios validez de constructo estudiados, estos resultados tienen sólo un alcance preliminar, siendo necesario efectuar nuevos análisis que permitan establecer su replicabilidad y estabilidad en una muestra mayor. Especialmente relevante se vuelve la realización de un Análisis Factorial Confirmatorio en una segunda fase de trabajo. También sería deseable estudiar la estabilidad del instrumento realizando evaluaciones sucesivas a una misma muestra de sujetos (test-retest). 
La correlación significativa entre las actitudes frente al agravio y los síntomas de Burnout, también mostró un patrón acorde a lo postulado por la teoría (Maslach y Jackson, 1981). Los docentes afectados por el Burnout tienden a desarrollar, por su propia situación de desgaste, actitudes negativas como la irritabilidad, el nerviosismo, la baja tolerancia a la frustración, la hostilidad y el cinismo, que claramente se oponen a las actitudes de naturaleza prosocial. Por lo tanto, el síndrome de Burnout predispondría al docente a un estado de vulnerabilidad y susceptibilidad emocional, que lo haría más proclive a manifestar actitudes de Hostilidad, Venganza y Resentimiento, y menos propenso a mostrar actitudes eficaces ante un agravio ocasionado por el alumno.

En cuanto a la confiabilidad, se ha podido demostrar que los tres dominios generales que la componen presentan de una consistencia interna apropiada.

En síntesis, el cumplimiento satisfactorio de estos criterios psicométricos habilita la realización de análisis más exigentes y de mayor alcance que permitan la emergencia de una versión definitiva que resulte válida y confiable para ser utilizada en población docente. 


\section{Referencias}

Abad, S. (2002). Acerca de las conductas violentas en la escuela. En: Revista Ensayos y Experiencias, 44:30-43.

Comrey, A. L., y Lee, H. B. (1992). A first course in factor analysis. Hillsdale: Erlbaum.

Ferrando, P. J., y Anguiano-Carrasco, C. (2010). El análisis factorial como técnica de investigación en psicología. En: Papeles del Psicológo. Centro de investigación para la evaluación y medida de la conducta. Universidad 'Rovira i Virgili', 31(1):18-33.

Gómez, A. (2014). La violencia de alumnos hacia maestros en escuelas secundarias de Colima, México. En: Pensamiento Educativo. Revista de Investigación Educacional Latinoamericana, 51(2):19-34.

Gorsuch, R. L. (1983). Factor analysis (2nd. ed.). Hillsdale: Erlbaum.

Lloret-Segura, S., Ferreres-Traver, A., Hernández-Baeza, A., \& Tomás-Marco, I. (2014). El análisis factorial exploratorio de los ítems: una guía práctica, revisada y actualizada. En: Anales de psicología, Universidad de Murcia (España), 30(3):1151-1169.

Marín, M. (2002). Aspectos psicosociales de la violencia en el contexto educativo. En: Revista Aula Abierta, 79:85-107.

Maslach, C., \& Jackson, S. E. (1981). The measurement of experienced burnout. En: Journal Violencia escolar. En: Revista Latinoamericana de Estudios Educativos. Centro de Estudios Educativos A.C. (México), Vol. XL (1):53 - 68.

Moreno, J., y Pereyra, M. (2000). Cuestionario de Actitudes Frente a Situaciones de Agravio. Universidad Adventista del Plata, Libertador San Martín, Entre Ríos. Of ocupational behavior. University of California, Berkeley, 2(2):99-113.

Rodriguez, L. M., y Moreno, J. E. (2013). Profundidad del daño, tiempo transcurrido y perdón ante un agravio. En: Acta Académica. V Congreso Internacional de Investigación y Práctica Profesional en Psicología XX Jornadas de Investigación Noveno Encuentro de Investigadores en Psicología del MERCOSUR. Facultad de Psicología - Universidad de Buenos Aires, Buenos Aires. Universidad Católica Argentina, sede Paraná y CIIPMECONICET. Recuperado de: http://www.aacademica.org/000-054/347.

Silar, M. (2004). El hombre capax affectionis. Hacia una filosofía del perdón. Seminario impartido en el Grupo de Estudios Peirceanos, Facultad de Filosofía y Letras, Universidad de Navarra, España. Recuperado de: http://www.unav.es/gep/HombreCapaxAffectionis.html. 
Vázquez, A., Manassero, M. A., y Acevedo, J. A. (2005). Análisis cuantitativo de ítemes complejos de opción múltiple en ciencia, tecnología y sociedad: escalamiento de itemes. En: Revista Electrónica de Investigación, (1), 1-31. 